
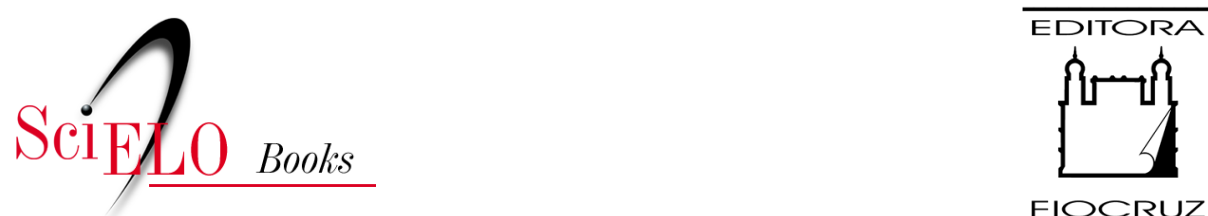

FIOCRUZ

\title{
1. Proteção Social Alemã
}

\author{
Lígia Giovanella
}

\section{SciELO Books / SciELO Livros / SciELO Libros}

GIOVANELLA, L. Proteção Social Alemã. In: Solidariedade ou Competição? Políticas e sistema de atenção à saúde na Alemanha [online]. Rio de Janeiro: Editora FIOCRUZ, 2001, pp. 31-51. ISBN: 978-65-5708-097-9. http://doi.org/10.7476/9786557080979.0004.

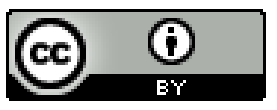

All the contents of this work, except where otherwise noted, is licensed under a Creative Commons Attribution 4.0 International license.

Todo o conteúdo deste trabalho, exceto quando houver ressalva, é publicado sob a licença Creative Commons Atribição 4.0.

Todo el contenido de esta obra, excepto donde se indique lo contrario, está bajo licencia de la licencia Creative Commons Reconocimento 4.0. 


\section{Proteção Social Alemã}

A organização do estado de bem-estar alemão é paradigmática de um dos tipos ideais de caracterização dos sistemas de proteção social modernos: meritocrático-corporativo (Titmuss, 1958), conservador (Esping-Andersen, 1990) ou de seguro social (Fleury, 1994; Werneck Vianna, 1995). ${ }^{17}$

Criado por Bismarck ao final do século XIX, o seguro social alemão tem sua gênese e a estrutura intimamente ligadas ao conflito capital-trabalho. ${ }^{18} \mathrm{Na}$ Alemanha, durante o processo conservador de transição para o capitalismo, o Estado autoritário tomou para si a responsabilidade pela segurança social e incluiu gradualmente a população dependente do trabalho assalariado na solidariedade obrigatória. ${ }^{19}$

A política social de Bismarck, para além do enfrentamento da questão social, conformava uma proposta intencional de organização corporativa da sociedade - corporações submetidas ao Estado - e de ampliação do controle social. Buscava combater o avanço da social-democracia através da "realização dos pontos das reivindicaçōes socialistas, que fossem adequados e compatíveis com as leis do Estado e da sociedade" (Bismarck apud Oliveira, 1995:25). ${ }^{20}$

17 Parte deste capítulo foi publicada na forma de artigo nos Cadernos de Saúde Pública (Giovanella, 1999).

18 Para análise detalhada das modalidades de transição para o capitalismo e padrōes de incorporação das demandas sociais, assim como um histórico da constituição do sistema de proteção social alemão, consulte Fleury, 1994.

19 A solidariedade espontânea de classe, expressa em Caixas autônomas de ajuda mútua organizadas pelos trabalhadores, foi incorporada/tomada pela solidariedade coercitiva do sistema de seguro social estatal.

20 A introduçāo do seguro social sofreu forte oposiçāo dos trabalhadores social-democratas, o que pode ser entendido, lembrando-se o contexto de luta política bismarckiana contra a social-democracia. 
Centrado na esfera do trabalho assalariado, o Estado de Seguro Social (Sozialstaat) assegurava direitos sociais aos cidadãos na medida da sua participação no mercado de trabalho, da mesma forma que no caso da cidadania brasileira - que seguiu esse modelo -, "regulada" (Santos, 1979) pelo lugar que o indivíduo ocupa no processo produtivo.

Ao condicionar direitos ao mérito individual, o seguro social consolidou grupos com diferentes status e privilégios. A necessidade de ajuda passou a ser avaliada como merecida ou não, cristalizando-se diferenças sociais com suas respectivas conotações morais (Koch, 1995).

A centralidade da política social no mundo do trabalho assalariado caracterizou-se de três maneiras, de acordo com o direito a benefícios sociais: "é dependente de trabalho assalariado anterior; pressupõe disposição para o exercício de trabalho assalariado; e o valor dos benefícios é definido segundo os rendimentos do trabalho" (Nullmeier \& Vobruba, 1995:12).

Esta ênfase no trabalho assalariado fez com que princípios norteadores das relações de trabalho fossem transpostos para a base da política social. A concepção de que o mérito/remuneração de cada indivíduo corresponderia à qualidade $\mathrm{e}$ extensão de sua produção tornou-se fundamento do sistema de seguro social. Assim, da mesma forma que no mercado de trabalho, a remuneração estaria correlacionada à capacidade de produção de cada indivíduo, no scguro social, os benefícios deveriam ser equivalentes à sua capacidade de contribuição.

Desse modo, a maioria das formas de promoção de eqüidade no seguro social relaciona-se à integração no mercado de trabalho. Contudo, as regras que definem limite máximo para desconto da contribuição e para obrigatoriedade de participação nos scguros, assim como a não integraçāo de trabalhadores com vínculo precário (a chamada 'ocupação mínima'), quebram esta vinculação na parte superior e inferior desse mercado (Nullmeier \& Vobruba, 1995). Os assalariados de alta remuneração são liberados da solidariedade coercitiva, e os trabalhadores com baixa integração - trabalho de tempo parcial com remuneração mínima - são excluídos da solidariedade.

Como a cidadania social alemã é regulada pela inserção no processo produtivo, a garantia de direitos sociais corresponde a um "processo de inclusão". Este, porém, não é antagônico à exclusão, mas sim concomitante. Um sistema de seguro social, ao mesmo tempo em que assegura transferências e serviços com base em determinados direitos justificados, priva da garantia desses direitos aqueles que não preenchem os requisitos: "cada inclusão é acompanhada por uma exclusão (Luhmann), pois cada programa social condicional é construído segundo o esquema 'se-entâo', no qual a negação 'se não-entāo não' está implícita” (Offe, 1990:185).

O seguro social alemão se caracteriza por expansão e inclusão progressivas. Entretanto, em sua origem, dirigia-se a um grupo que, embora crescente e 
economicamente importante, representava ínfima parcela da população: os trabalhadores assalariados (blue collars). ${ }^{21}$ No processo de expansão foram incluídos gradualmente novos setores da população e expandidos os benefícios e serviços cobertos. Houve o reconhecimento cumulativo de necessidades a serem garantidas - doença (1883), ${ }^{22}$ acidentes de trabalho (1885), velhice (1891), desemprego (1927) e cuidados de longa duração (1994). Ampliou-se o círculo de beneficiários por meio da inclusão de novos grupos profissionais, expandindo-se a proporção de segurados na população total. Ao mesmo tempo, o nível de renda e a abrangência da cesta de serviços afiançados por cada ramo cresceram gradualmente (Alber, 1982).

Além da expansão e inclusão progressivas, a história do seguro social alemão foi igualmente marcada pela estabilidade do modelo de seguro social. O sistema criado demonstrou alta estabilidade ao manter sua estrutura básica durante mais de cem anos. Sobreviveu à queda do império, à jovem e tumultuada república de Weimar, à inflação de 1923 e à grande depressão do início dos anos 30 , ao nazismo (Terceiro Reich), bem como à derrota nas duas guerras mundiais e à ocupação aliada (Wysong \& Abel, 1990). E, até o momento, tem sobrevivido ao neoliberalismo.

Em termos gerais, o seguro social alemão caracteriza-se pela participação compulsória dos trabalhadores assalariados mediante contribuições proporcionais aos salários até um limitc máximo definido por lei e pela administração autônoma dos órgãos de seguro, os quais, em geral, são geridos de forma paritária por trabalhadores e empregadores, modalidade pela qual também participam nas contribuições em quase todos os seus ramos. Os órgãos de seguro social são públicos, mas não estatais, e sua atuação é regulada e controlada pelo Estado.

\section{Princípios Constitutivos do Seguro Social}

O seguro social constituiu-se com base nos princípios de 'equivalência' característico de qualquer seguro -, de 'solidariedade' - por pressupor alguima redistribuição - e de 'subsidiariedade', quc define a ação estatal como complementar.

Pelo princípio de equivalência, os benefícios são vinculados às contribuições prévias, e diversas instituições são conformadas, dirigidas a diferentes grupos de trabalhadores. O princípio da subsidiariedade, por influência da igreja, serve

21 Em 1885, 10\% da população do Reich (cerca de 4,5 milhões de pessoas) contribuía para o seguro-doença. Em 1913, cerca de $25 \%$ da população. O principal benefício era o auxíliodoença a partir do terceiro dia, correspondendo a, no mínimo, $50 \%$ do salário médio da regiäo (Oliveira, 1995).

22 A 'Lei do Seguro Doença dos Operários' - Gesetz betreflend die Krankenversicherung der Arbeiter - foi promulgada em 15.06.1883 e entrou em vigor em 1.12.1884. 
para enfatizar que o Estado somente interferirá quando a capacidade da família estiver exaurida, envolvendo responsabilidade de cada indivíduo. O princípio da solidariedade torna as contribuições proporcionais à renda, bem como a concessão dos benefícios de acordo com as necessidades, produzindo redistribuição.

Esses princípios estruturantes do Seguro Social de Doença - de equivalência, solidariedade e subsidiariedade, analisados a seguir - têm vigência desde a sua criaçāo e se manifestam com ênfases diferenciadas no transcorrer do tempo.

\section{Equivalência}

Este é o princípio básico de qualquer tipo de seguro privado. Segundo o princípio da equivalência, o volume e a extensāo dos benefícios recebidos devem corresponder/eqüivaler ao valor das contribuiçōes pagas pelo segurado. A partir de estimativa dos riscos, efetua-se o cálculo das contribuições a serem pagas pelos segurados, de modo que estas sejam suficientes para cobrir as necessidades de pagamento de prêmios. Na constituição do seguro social, todavia, este princípio tem distinta validade.

Enquanto o seguro individual representa uma resposta à possibilidade de ocorrência de danos que ameaçam a empresa ou o indivíduo e que colocam em questão a ação utilitarista máxima de cada um, visto como homo economicus, e o benefício de um seguro privado é, $\mathrm{em}$ geral, a garantia de compensação financeira no caso de o indivíduo sofrer o dano assegurado - ao mesmo tempo em que a certeza de garantia do benefício aumenta a segurança do indivíduo quanto ao futuro,$-{ }^{23}$ por sua vez, o seguro social reduz a insegurança social por meio da compensação de riscos politicamente definidos. A especificidade do risco no seguro social consiste no reconhecimento coletivo de situaçōes de vida como provocadas pela insegurança social - produção social objetiva dos riscos - e a vinculação das mesmas ao direito a benefícios sociais estatais (Lauer-Kirschbaum \& Rüb, 1994).

$\mathrm{Na}$ organização da sociedade industrial capitalista, os indivíduos encontram-se submetidos a variados riscos, cujas origens não podem ser atribuídas apenas a comportamentos individuais inadequados, o que torna pouco plausível que os atingidos possam enfrentar e superar isoladamente o seu destino físico e material. Além disso, o enfrentamento coletivo dos riscos decorre de suas conseqüências negativas coletivas, seus custos externos (Offe, 1990).$^{24}$ Ocorre, assim, o reconhecimento dos riscos e de suas formas de enfrentamento pelo Estado central

23 A criaçāo da expectativa de segurança, ou seja, a redução do desconhecimento a respeito das consegüichncias de um provável perigo que o seguro proporciona pode ser considerada integrante daquele benefício (Lauer-Kirschbaum \& Rüb, 1994).

24 Considerando-se apenas a perspectiva da discussão dos riscos, sem entrar aqui na análise quanto à origem e às determinações da política social, muito mais complexa, que não ć objeto deste estudo. 
e estes passam a integrar a sua agenda. No seguro social, a definição de contribuições envolve aspectos distintos daqueles do cálculo de prêmios do seguro privado, condicionando o princípio de equivalência.

O princípio da equivalência decorre não apenas da lógica de seguro, mas também da transposição de princípios regentes das relaçōes de trabalho para a política social. Embora a remuneração do trabalho corresponda ao valor mínimo necessário para sua reprodução e não ao valor produzido/agregado, existe certa correspondência entre a remuneração e a quantidade de trabalho realizado. Desse modo, a concepção de que há relação de equivalência entre a quantidade de trabalho feito pelo indivíduo e sua remuneração correlaciona-se à acepção, no seguro social, de que os benefícios devem corresponder às contribuiçōes.

Ao mesmo tempo, segundo Offe (1990), o princípio de equivalência garantiria apoio ao modelo de proteção social. Ao vincular o direito benefícios às contribuiçōes, tal princípio evita o gozo dos mesmos por pessoas não autorizadas pelas contribuiçōes. Quando prevê que o nível de benefícios deve ser correspondente às contribuiçōes, previne uma redistribuição interna proposital entre os participantes de maior e menor renda. Para Offe (1990), o conhecimento antecipado da redistribuição que ocorre de fato ao interior da comunidade de segurados poderia corroer a legitimidade do sistema de proteção.

Entretanto, no seguro social, a equivalência entre contribuições e bencfícios é rompida com a finalidade de compensação social. A vigência concomitante da solidariedade ameniza o exercício da equivalência. Contribuiçōes e benefícios estão relacionados aos salários; contudo, não há equivalência imediata entre ambos. O segurado não recebe de volta o valor da conta individual de contribuiçôes capitalizada no transcorrer dos anos. Uma 'necessidade' básica de manutenção do padrão de vida 'merecido' pela sua participação no mercado de trabalho - conquistado durante a vida produtiva - é definida politicamente.

A previdência social é o ramo do seguro social alemão em que a equivalência tem maior importância. A fórmula para cálculos de aposentadoria é apresentada como expressão da configuração de benefícios equivalentes às contribuições, porém, não há relação constitutiva direta entre a contribuição e o valor da aposentadoria. A posição que o segurado ocupa na hierarquia de renda justifica o valor da participação individual no volume financeiro colocado posteriormente à disposição, o qual, por sua vez, é determinado conforme algum objetivo de segurança social (Kolb apud Nullmeier \& Vobruba, 1995).

O nível do salário de contribuição - a que devem corresponder as transferências financeiras dos diversos ramos do seguro social - tem por base não apenas o 'mérito', mas também certa concepção de 'necessidade' a ser suprida, que é, por sua vez, politicamente definida (Nullmeier \& Vobruba, 1995). Por conseguinte, está presente uma concepçāo de garantia de direitos conforme a necessidade 
(Bedarfsgerechtigkeit) nos diversos ramos do sistema, como, entre outros, assistência médica completa $\mathrm{em}$ caso de doença, garantia do padrão de vida em níveis reduzidos no seguro-aposentadoria depois do cumprimento do tempo de trabalho - $68 \%$ em aposentadoria padrão após 45 anos de seguro - e no seguro-desemprego ( $60 \%$ no seguro-desemprcgo c $53 \%$ no auxílio-desemprego). Pode-se, portanto, considerar que o princípio de equivalência no seguro social vige de forma mediada, 'equivalência mediada'.

No seguro social de doença, a solidariedade suplanta a equivalência, desvinculando o direito à atenção do valor das contribuiçōes. Neste ramo do seguro social, o princípio de equivalência vige apenas para o auxílio-doença que corresponde a determinada proporção dos salários de contribuiçāo. Vigora uma equivalência igualmente mediada, pois os benefícios não correspondem diretamente ao valor das contribuições, uma vez que as transferências nāo têm por base fundos individuais capitalizados, e o nível de reposição salarial, em caso de doença, é definido politicamente.

Originalmente, o princípio de equivalência tinha maior significado também para o Seguro Social de Doença $\mathrm{cm}$ virtude da maior participação das transferências financeiras no conjunto de gastos. Embora o pagamento de benefícios em espécie, especialmente o auxílio-doença, permaneça como encargo do Seguro Social de Doença, sua importância relativa diminuiu no transcorrer dos anos devido à expansão do catálogo de açōes médico-sanitárias e à conseqüente redução dos benefícios em dinheiro. Ao mesmo tempo, em razão de mudanças na legislação, as transferências financeiras desvinculadas do valor das contribuiçōes, em particular aquelas relativas à política familiar e à maternidade, passaram a fazer parte do seguro social, o que diminuiu a importância do princípio de equivalência para a própria definição do valor das transferências financeiras.

No debate contemporânco, o apelo ao princípio de equivalência no Seguro Social de Doença serviu para a defesa da exclusāo destes últimos benefícios, tidos como "estranhos ao seguro" (Arnold, 1993:28). Estes seriam da compctência estatal direta e deveriam ser financiados com recursos fiscais, de modo a aliviar o caixa dos órgãos de administração autônoma dos seguros sociais.

Embora certa equivalência venha a ser inevitável na sociedade capitalista, é importante nāo esquecer que o nível a partir do qual ela deve vigorar ć politicamente definido. O ponto de equilíbrio entre equivalência e necessidade constitui objeto de constante disputa.

\section{Solidariedade}

Diversos significados e empregos são atribuídos à solidariedade: não é apenas preceito moral, mas sim palavra de ordem, vínculo de classe, justificativa 
para a redistribuição que ocorre no interior do seguro social. O princípio da solidariedade, ao contrário da equivalência, significa que o ônus de cada um deve ser redistribuído entre os membros da comunidade solidária.

A palavra solidariedade origina-se de sólido (latim solidum), o que the imprime o sentido de estar em bases firmes. Estar com outros na mesma situaçāo, ter interesses comuns. A expressão do senso comum que talvez melhor defina solidariedade é: "um por todos e todos por um" (Schönig, 1996:101). Nesta asscrtiva, solidarizar-se significa colocar-sc conscientemente no lugar do outro. Identificar-se com o destino do outro. O que acontece ao outro é experimentado como sc tivesse ocorrido a cada um. $\mathrm{O}$ indivíduo se identifica com o grupo e o grupo se identifica com o indivíduo (Baumgartner, 1997). Assim, solidariedade é relação de responsabilidade entre pessoas unidas por interesses comuns, de maneira que cada elemento do grupo sinta a obrigaçăo moral de apoiar os outros.

Como princípio moral na tradição judaico-cristã, a solidariedade vincula o indivíduo a uma comunidade fundamental, na qual todos - homens e mulheres são portadores de dignidade pessoal em virtude de serem criados por Deus à Sua imagem e semelhança (Baumgartner, 1997). Nesta tradição, como tal princípio advém da comunhão de pertencimento à comunidade humana de seres dignos, recebe valor universal. Refere-se a todos os seres humanos, valendo para toda situação em que a realização de vida digna esteja obstaculizada.

$\mathrm{Na}$ tradição socialista, a solidariedade provém do pertencimento à mesma classe social. $O$ interesse comum de classe imprime a cada um a obrigação moral de responsabilizar-se pelo destino do outro. Este é o sentido em que o termo solidariedade foi empregado nas lutas dos trabalhadores no século passado, como solidariedade de classe social. Nesta acepçāo, o reconhecimento de um 'nós' inclusivo, de um 'estamos no mesmo barco', e a identificação com o destino do outro são decorrências do pertencimento comum de classe.

Ao final do século passado, esta solidariedade espontânea de classe expressava-se em Caixas autônomas de ajuda mútua, organizadas pelos trabalhadores, que foram incorporadas na legislação social. Alguns autores, por isso, referem-se a uma solidariedade coercitiva em razāo de a filiaçāo ao seguro social ser legalmente obrigatória e ter substituído iniciativas próprias dos trabalhadores (Koch, 1995). A solidariedade teria nesta acepção duas facetas. Uma, coercitiva, imposta pelo sistema de seguro social. Outra, espontânea, de classe, democrática/política, exercitada pelos trabalhadores.

Solidariedade significa responsabilização coletiva pela garantia de uma vida digna; é produto cultural, fruto do processo civilizatório, e como tal, necessita ser reiteradamente preservado e recriado. Não é suficiente, porém, que a solidariedade se apresente como consciência moral; é preciso que seja institucionalizada 
em reais possibilidades de comportamento ${ }^{2.5}$ (Kühn, 1995c). Nesse sentido, a solidariedade decorre de uma postura igualitária e civilizatória que se materializa em instituições de bem-estar.

É com sua institucionalização nos diversos ramos do seguro social que o princípio de solidariedade vem a ser implicitamente definido. Operacionalmente, para o seguro social como um todo, o princípio da solidariedade é vínculo que responsabiliza cada segurado pelos encargos do conjunto (Schulenburg, 1990).

Em virtude da centralidade no trabalho assalariado, que estratifica os direitos conforme a inserção no processo produtivo, o seguro social tem por base a solidariedade de grupo. Os grupos são constituídos de modo mais ou menos homogêneo. Definem-se conforme a posição ocupada na produção, excluindo-se do seguro obrigatório as remunerações muito altas e muito baixas. Deste modo, o princípio da equivalência condiciona a solidariedade e esta se exerce de forma partida. Esta maneira de segmentação na garantia da cidadania social - segundo a inserção no mercado de trabalho - é característica do modelo de seguro social. Neste modelo, a redistribuição típica ocorre apenas entre os integrantes de mesmo grupo ocupacional. Tradicionalmente, o modo de inclusão no seguro social promoveu a distinçāo entre os operários, empregados e trabalhadores dos diversos ramos da produção. Estes estariam submetidos a diferentes riscos e deveriam formar grupos distintos.

A conformação de grupos com certa homogeneidade tendo como meta facilitar o exercício da solidariedade grupal é também a justificativa para a exclusão de grupos de assalariados com remunerações muito altas e muito baixas, assim como para a definição de nível máximo de renda para as contribuições obrigatórias. Com a definição destes limites, o apelo a contribuir solidariamente não tensionaria demais os interesses individuais e não afetaria a coesão do grupo. Estas exclusōes evitariam a sobredistensão da disposição dos indivíduos de maior renda para a solidariedade. Ao mesmo tempo, estes limites recortam o grupo solidário nos extremos superiores e inferiores da escala de estratificação social.

O significado do exercício da solidariedade modificou-se no processo de expansão do seguro social. Inicialmente, a comunidade solidária era entendida como composta por um grupo de indivíduos de mesma camada social, os operários industriais. Atualmente, a redistribuição se dá entre diferentes estratos sociais.

Tal evoluçāo da proteção social da Alemanha subentende a ampliação da solidariedade de grupo, pois tanto os grupos tornaram-se cada vez mais abrangentes, como o financiamento mediante recursos fiscais adquiriu maior importância com o passar do tempo.

2.5 Solidariedade implica ainda que em uma sociedade pessoas possam ser mais fracas ou não produtivas e necessitar de ajuda para uma vida digna, sem que sejam discriminadas ou marginalizadas por isso. 
O Seguro Social de Doença é o ramo do seguro social em que o princípio da solidariedade adquire maior importância, ao passo que nas outras áreas do seguro social vigora uma "equivalência mediada pela solidariedade", no Seguro Social de Doença impera o princípio da 'necessidade', o que o torna um sistema cunhado pela solidariedade.

Os segurados recebem assistência na medida de suas necessidades de saúde c contribuem de acordo com sua capacidade financeira. Idade, sexo, risco de adoecer, estado de saúde e composição familiar não são levados em conta no cálculo das contribuições. As contribuições dos segurados, como proporção de seus salários, são 'dependentes' de suas possibilidades financeiras. O direito à atenção conforme a necessidade é 'independente' do valor das contribuiçōes, isto é, da capacidade de financiamento de cada indivíduo.

A vigência do princípio da solidariedade produz redistribuição ao interior do Seguro Social de Doença. Contribuições proporcionais à renda e direito a benefícios correspondentes às necessidades levam a efeitos distributivos. Entre os incluídos, os trabalhadores em melhor situação financeira contribuem para a satisfação das necessidades dos economicamente mais fracos. Os sadios ou os que adoecem com menos freqüência pagam para os doentes; os segurados sem dependentes, para os segurados com dependentes; e, por fim, os mais jovens, para os mais velhos.

A redistribuição é principalmente horizontal, isto é, ocorre ao interior de uma mesma 'comunidade' de trabalhadores submetidos a certos riscos comuns. Embora seja também vertical - quando efetuada desde os grupos que recebem melhor remuneração para os que obtêm pior remuneração - não se realiza diretamente e de modo mais intenso entre os grupos mais bem remunerados e aqueles em pior situação econômica. A redistribuição efetua-se com primazia entre grupos com baixo risco de adoecer e maior remuneração e os grupos com alto risco de adoecer e baixa renda.

É igualmente uma redistribuição entre jovens e velhos, o chamado contrato intergeracional. O Seguro Social de Doença dos aposentados é deficitário. A receita proveniente das contribuições pagas por aposentados não é suficiente para cobrir suas despesas com saúde. Uma parte das contribuições dos trabalhadores ativos - equivalente a cerca de três pontos percentuais - financia o déficit do Seguro Social de Doença dos aposentados (Oldiges, 1994).

Tradicionalmente, esta redistribuição limitava-se ao interior do grupo de segurados de cada uma das Caixas de Doença (Krankenkasse), organizadas por ocupação, região ou empresa e com adscriçāo compulsória de clientelas. Contudo, a partir de 1993, ampliou-se a redistribuição para o conjunto do sistema por meio da Lei da Estrutura da Saúdc. Com o objetivo de estimular a competição, esta lei estendeu a liberdade de cscolha das Caixas, que anteriormentc era restrita a certos 
grupos ocupacionais, para a maioria dos segurados. Por meio deste mecanismo, a redistribuição rompeu os limites da comunidade de segurados de cada Caixa, estendendo-se ao conjunto de segurados. ${ }^{26}$

Os segurados reconhecem a validade da redistribuição, expressão do princípio de solidariedade, que ocorre no interior do sistema. Pesquisas de opiniāo e análises qualitativas têm demonstrado que o efeito redistributivo em favor dos idosos, doentes crônicos e familiares dependentes é desejado pelos segurados (Ulrich; Wemken \& Walter, 1994; Rinne \& Wagner, 1995; Braun, 1995; SVR, 1994). A aceitação da redistribuição, porém, não decorre apenas do alto valor atribuído à solidariedade. As justificações normativas para a solidariedade têm papel subordinado para a aceitação do sistema. Cálculos comuns, não financeiros, de interesse individual é que garantem semelhante aceitabilidade (Ulrich, Wemken \& Walter, 1994). Trata-se de um cálculo de interesse intertemporal, que torna aceitável o sistema solidário: a expectativa de utilização e a confiança na garantia de atenção futura.

Embora poucos sejam os que se julgam na posição de favorecidos, a consideração da redistribuição pelos segurados como primariamente intertemporal (da juventude para a velhice) mais do que interpessoal, bem como a indesejabilidade da mudança de posição, pois ninguém deseja ficar doente para utilizar mais serviços, faz com que a posição de pagante-líquido, aqueles que pagam mais do que gastam com a utilizaçāo, seja apreciada como positiva. A garantia da possibilidade de uso segundo o princípio da necessidade, na qual os segurados incluem suas expectativas de utilização futura, torna a redistribuição aceitável. A compensação é estar sadio, e o fator tempo exerce aí papel fundamental. O sistema garante a reciprocidade no caso de mudança de posição em razāo da expectativa de maior utilização futura. Quanto mais idoso for o indivíduo, maior será a probabilidade da necessidade de atenção, havendo assim a perspectiva de redistribuição intertemporal em benefício de cada um.

Desse modo, os segurados têm confiança na estabilidade da garantia de proteção $\mathrm{cm}$ situações futuras que ultrapassem sua capacidade de pagamento. Valorizam de modo positivo suas experiências de utilização e levam em conta que, no futuro, a atenção da qual necessitarem estará garantida, demonstrando alta satisfação com o sistema solidário (Ulrich; Wemken \& Walter, 1994; Rinne \& Wagner, 1995; Braun, 1995; SVR, 1994). Para a maioria deles, o sentimento de segurança tem base na forma de organização do sistema, tida como a mais adequada para o asseguramento do risco de doença: um sistema obrigatório e solidário, no qual a futura utilização não se vincula à capacidade de financiamento individual e dependerá da necessidade.

26 Ao mesmo tempo, para evitar a competição predatória, criou-se um mecanismo de transferências financeiras entre as Caixas, com o objetivo de compensaçăo da estrutura diferenciada de riscos de seus segurados. Este mecanismo levou à reduçāo da amplitude das diferenças existentes entre as taxas de contribuição das diversas Caixas. 


\section{Subsidiariedade}

Dentre os princípios básicos do Scguro Social de Doença, o Código Social alemão (Sozialgesetzbuch-SGB), inclui também a 'subsidiariedade'. Segundo este princípio, a responsabilidade primcira pela saúde é do indivíduo e de sua família; assim, "a compensação solidária deve ser uma ajuda para a autoajuda" (BMAS, 1994:140).

O Livro V do Código Social, que congrega a legislação específica do Seguro Social de Doença, apela para a responsabilidade dos segurados:

Os segurados são co-responsáveis por sua saúde. Eles devem contribuir para a prevenção das docnças e para a superaçăo de suas conscqüências, através de uma conduta de vida conscientemente saudável c uma participação precoce $\mathrm{cm}$ medidas preventivas, bem como através da coopcração ativa no tratamento das docnças e na reabilitação. (SGB, 1993:109)

A vigência do princípio de subsidiariedade no Seguro Social de Doença significa que os riscos dos custos da doença somente devem ser garantidos por uma comunidade solidária maior quando o indivíduo ou sua família, por si mesmos, não estivcrem $\mathrm{cm}$ condições de superar o risco. ${ }^{27}$ Este princípio justifica a definição do limite máximo de renda para a obrigatoriedade de participação no seguro social. Quem recebe acima da quantia delimitada por lei, deve prover por meios próprios sua proteção mediante a compra de seguro privado on a formação de poupança.

No decorrer de mais de cem anos de história do Seguro Social de Doença, o princípio da subsidiariedade perdeu a força na estruturação do sistema. Originalmente, este princípio tinha maior importância. Sua preponderância inicial explica o caráter restritivo do sistema: a pouca abrangência do grupo de segurados e a baixa extensão dos benefícios (Schulenburg, 1990). Seu significado passou, de modo gradual, para segundo plano com a inclusão de parcela cada vez maior da população e com a ampliação do catálogo de açōes médico-sanitárias c benefícios de ações que, por tradição, constituíam encargo da família.

Os cuidados dispensados aos velhos, por cxemplo, tradicionalmente quase que restritos à comunidade familiar, foram assumidos aos poucos pelo segurodoença até 1994, quando se criou novo ramo do seguro social: o seguro social de cuidados de longa duração (Pflegeversicherung), que assegura cuidados domiciliares e asilares, sobretudo para idosos. Este caso exemplifica uma necessidade antes coberta de forma subsidiária e que foi incorporada ao sistema solidário.

27 A palavra subsidiaricdade origina-se do latim subsidium, que significa ajuda. Scu cmprego inicial foi militar, referido à tropa de retaguarda, a qual entrava en ação quando as tropas de frente nẫo cram sulicientes. Por isso há a compreensão de subsidiariedade como emprego de forças de segunda linha, de ajuda que vem $\mathrm{cm}$ segundo lugar. 
Atualmente, é na assistência social que vigora integralmente o princípio da subsidiariedade. A assistência social, que na verdade é externa e complementar ao sistema de seguro social, elucida o princípio da subsidiariedade. O Estado só pode intervir quando o indivíduo e sua família estão impossibilitados de assegurar a subsistência por meios próprios.

A assistência social tem como base o financiamento fiscal sem contribuições diretas dos beneficiários, mas o auxílio só se concretiza pela comprovação da carência. Uma prova da necessidade é decisiva para o direito ao benefício e para definir o tipo e a extensão do auxílio. A assistência social é uma ajuda individualizada, ajustada à situação de cada caso, e deveria ser, ao mesmo tempo, subsidiária: complementar à ajuda própria e ao auxílio dos familiares (Frerich, 1996).

Em razão da ampla cobertura e da extensão do catálogo de açōes, o princípio da subsidiariedade não caracteriza a prática atual do seguro social de doença. Entretanto, o recurso à subsidiariedade está hoje no centro da argumentação que intercede por políticas de contenção. No debate atual, alguns autores chegam a questionar se a grande maioria da população coberta pelo seguro social de doença é, de fato, necessitada de proteção (Schulenburg, 1990; Arnold, 1993).

A reatualização contemporânea do significado de subsidiariedade justifica uma breve recuperação do debate a respeito do significado desse termo, cuja discussão tem assumido diferentes ênfases e ainda é objeto de controvérsia.

Na Alemanha, o debate sociopolítico concernente à questão da subsidiariedade mantém a vitalidade há mais de um século (Deppe, 1985; Sachße, 1994) e reiteradamente tem adquirido importância em períodos de crise e altos índices de desemprego. Desde os anos 80, com a coalizão liberal-conservadora no poder, o tema tem sido evocado como fundamento para a maioria das reformas neoconservadoras.

As mais diferentes discussões acerca da ordem política deixam-se subsumir ao termo subsidiariedade: debates relativos à relação entre auto-responsabilidade $\mathrm{e}$ regulação estatal, assistência social pública $\mathrm{c}$ beneficente, pequenas redes sociais e grandes organizaçōes burocráticas. Desde o começo, a discussão a respeito da subsidiariedade desenvolve-se segundo duas linhas principais de interpretação: uma, de caráter liberal, de defesa da 'livre iniciativa', e outra, de maior influência na implementação deste princípio na Alemanha, advinda da doutrina social católica.

Uma das raízes do princípio de subsidiariedade encontra-se no pensamento liberal dos séculos XVIII e XIX (Sachße, 1994). Na concepçāo liberal, a sociedade era concebida como autônoma: uma sociedade de trocas auto-reguladas pelas leis de mercado, na qual o indivíduo - sujeito livre de qualquer cocrção e autoresponsável - se socializa. O Estado, concebido como esfera distinta da sociedade e responsável pelo exercício legítimo da violência, teria como tarefa essencial a defesa das condições gerais de sociabilização (Vergesellschaftung) da sociedade de 
trocas. A garantia da existência deveria ser deixada à iniciativa própria do indivíduo, porque, na concepção liberal, a reprodução pertence à esfera privada: é responsabilidade primária do indivíduo. A responsabilidade do Estado deveria restringir-se a situações excepcionais, nas quais o indivíduo não consegue garantir sua existência por meios próprios, suprindo suas necessidades no mercado. Ou seja, a atuação do Estado deveria ser 'subsidiária', o que garantiria a liberdade individual (Sachße, 1994).

Como a ajuda é subsidiária, é complementar, vem em segunda linha, a necessidade tem de ser comprovada. A subsidiariedade legitima os chamados testes de meios como condiçâo de elegibilidade para acesso aos benefícios. Este princípio - para os liberais, antes de tudo, defesa da esfera privada - é que permite a intromissão, por vezes drástica, do Estado na vida privada dos indivíduos (Deppe, 1985:85).

Em síntese, na tradição do pensamento social liberal, subsidiariedade refere-se à distribuição da responsabilidade social entre indivíduo, comunidade e Estado, em que a auto-responsabilidade individual tem precedência sobre a proteção e a segurança estatais (Sachße, 1994).

A outra linha de interpretação do princípio de subsidiariedade está no pensamento social católico. $\mathrm{Na}$ Alemanha, pela forte ascendência da doutrina católica no que se refere à difusão deste princípio, a vigência da subsidiariedade adquire conotação diferente da concepção plenamente liberal.

O catolicismo social alemão delimitou seu campo político em contraposição tanto ao liberalismo como ao socialismo (Sachße, 1994). Como a igreja exerceu influência na conformação do próprio Estado Social, a subsidiariedade serviu para enfatizar que o Estado somente deve interferir quando a capacidade da família estiver exaurida (Esping-Andersen, 1990). Embora há muito difundido pela doutrina católiça, o termo apenas foi explicitamente referido na 'Encíclica Social Quadragésimo Anno', de 1931, em contexto de avanço do socialismo e de expansão das doutrinas totalitárias na Europa (Baumgartner, 1997).

$\mathrm{Na}$ formulação clássica dessa 'Encíclica', subsidiariedade constitui o princípio de equilíbrio no campo de tensão entre a intervenção estatal e a liberdade societária. A liberdade de iniciativa individual é afirmada e a intervençāo estatal é considerada como de apoio, subsidiária às iniciativas individuais ou às de grupos subordinados (Baumgartner, 1997; Deppe, 1985).

Assim, o Estado não deveria subtrair às famílias as tarefas que elas mesmas estão em condições de preencher. Deveria promover e possibilitar a auto-ajuda, e retirar-se após o auxílio bem-sucedido para a auto-ajuda (Schönig, 1996). ${ }^{28}$

28 Além disso, para a igreja católica, a subsidiariedade seria o corretivo contra o excessivo coletivismo: "a arma e o muro de proteção contra tudo o que o coletivismo é, e o que leva ao coletivismo" (Nell-Breuning, 1955 apud Deppe, 1985:84). 
Para outros representantes da doutrina social católica, no entanto, o princípio de subsidiariedade não afirma incondicionalmente que os indivíduos e as pequenas comunidades devam atuar primeiro e, somente após terem esgotado todas as suas forças é que a sociedade e o Estado devem intervir. Estes reformistas sociais católicos defendem que, antes que homens e mulheres possam colocar suas próprias forças em movimento, é necessário que a sociedade já tenha realizado uma série de medidas (Nell-Breuning, 1955 apud Engelhardt, 1994). Os riscos sociais não podem ser combatidos apenas pelo indivíduo; a sociedade deve garantir as precondições para a auto-ajuda. Para que o indivíduo possa empregar suas forças com êxito, torna-se necessário uma série de medidas prévias por parte do Estado.

Ao mesmo tempo, para a doutrina social católica, subsidiariedade e solidariedade não são noções contraditórias. Na acepção da doutrina social católica, o princípio da subsidiariedade seria imanente à idéia de solidariedade, pois a subsidiariedade enfatizaria a auto-responsabilidade do indivíduo năo apenas por si mesmo, mas também pelo conjunto da comunidade solidária à qual pertence (Baumgartner, 1997; Frerich, 1996).

O pensamento social católico diferencia-se do liberal clássico por destacar a necessidade de o Estado garantir as precondições para a promoção do desenvolvimento das potencialidades de cada família, no direito das comunidades menores em relação às maiores e na consideração da família e não do indivíduo como núcleo social básico (Deppe, 1985; Sachße, 1994). Estas são as características impregnadas no princípio de subsidiariedade na conformação da proteção social alemã em razão da influência da igreja católica. A questão da solução das necessidades via mercado, embora presente pelo lado liberal, tem menor destaque.

A discussão quanto à subsidiariedade assume diferentes ênfases no transcorrer do sćculo XX. Em geral, volta-se para a questão da assistência social, em que a igreja tem, por tradição, maior participação mediante suas entidades filantrópicas, mas adquire, na atualidade, relevância para a área da saúde, em especial, pela influência do neoliberalismo.

Contemporaneamente, alguns autores levantam a necessidade do debate acerca de uma nova subsidiariedade. Esta objetivaria a substituição da condução externa reguladora por uma autocondução situacional (Sachße, 1994; Wilke, 1996). Assim, a subsidiariedade descreveria a relação entre subsistemas autônomos auto-referenciados, que não conhecem nem ponta nem centro (Luhmann apud Sachße, 1994).

Na década de 1990, revitalizou-se o princípio da subsidiariedade, em especial, na área da saúdc. No debate acadêmico da área podem-se observar duas concepções distintas para a subsidiariedade. Uma, que defende entendimento mais restrito e apela para a auto-responsabilidade dos indivíduos (Arnold, 
1993; Graf von der Schulenburg, 1990). Estes devem, antes de tudo, procurar desenvolver a auto-ajuda e solicitar o apoio da família, antes de recorrer aos benefícios sociais do Estado.

Pode-se dizer que hoje o fortalecimento do princípio de subsidiariedade, expresso nas proposições de estímulo à auto-responsabilidade, corresponde à premissa neoliberal de mais mercado/menos Estado. Privatização de riscos, seletividade e focalização são defendidos, tendo como fundamento a subsidiariedade da intervenção estatal. O Estado deveria intervir focal e direcionadamente para minorar os problemas sociais apenas de estratos populacionais mais expostos aos riscos. ${ }^{29}$

Outra corrente, preocupada com a manutenção de um sistcma solidário, retoma as formulações relativas à subsidiariedade do político-social-católico Nell Breuninge e defende que a sociedade deve criar condições e pressupostos sob os quais cada indivíduo possa exaurir as próprias possibilidades. Nesta concepção, subsidiariedade deixa de ser antagônica à solidariedade, e as açōes devem ser prestadas por aquelas instituiçōes tidas como mais adequadas para tal (Reiners, 1987). Nessa linha de pensamento, a forma atual do seguro social de doença, organizado em órgãos autônomos da influência estatal dircta, é o sistema mais adequado para uma 'economia social de mercado', denominaçāo atribuída ao modelo alemão pelos democrata-cristãos.

\section{Ramos do Seguro Social Alemão}

Em cada um dos ramos do seguro social, os princípios estruturais deste modelo de proteçāo manifestam-se de forma diferente. Sua implementação distingue-se conforme as especificidades das atribuiçōes de cada ramo, e a ascendência de um princípio sobre os outros é diversa.

Como afirmado anteriormente, o sistema de seguro social alemão foi progressivamente ampliado desde a sua criação, tanto por meio da incorporação de novos riscos a serem cobertos e inclusão de novos grupos populacionais, como pela elevação dos níveis dos benefícios garantidos, mantendo, porém, suas características básicas. Atualmente é composto pelos seguros velhice, invalidez e morte (previdência), pelo seguro-doença, que inclui, além da atenção médico-sanitária, o auxílio-doença, bem como pelos seguros desemprego, de acidentes de trabalho e para cuidados de longa duração.

29 De todo modo, o recurso à subsidiaricdade não resultaria necessariamente na completa retirada do Estado. A subsidiariedade, mesmo em seu sentido mais estrito, tem dupla implicação. Ao mesmo tempo em que a intervenção estatal é complementar, a vigência da subsidiariedade significa que o Estado deve intervir: 
Nos seguros previdenciário, de desemprego e de acidentes, a maioria dos benefícios é garantida segundo o princípio de equivalência, ou seja, a extensāo dos benefícios depende do valor das contribuições. Assim, há certa correspondência entre benefícios e contribuiçōes. Contudo, nos seguros doença e de cuidados de longa duração, predomina o princípio de solidariedade: os segurados têm direito ao mesmo catálogo de serviços, independente do valor das contribuições. Além disso, para os diversos ramos, a autonomia administrativa (instituiçōes não diretamente estatais) tem como base o princípio da subsidiariedade. $\mathrm{Na}$ realidade, o princípio da subsidiariedade manifesta-se com toda força na assistência social, externa ao seguro social, cujos benefícios são assegurados somente quando o indivíduo e sua família não estão em condições de suprir as necessidades básicas por meios próprios.

As principais características do Seguro Social de Doença consistem em expressões mediadas destes princípios. $\mathrm{O}$ direito à utilizaçāo conforme as necessidades, sem relação com o valor das contribuiçōes, e o acesso direto às açōes e serviços de saúde, sem pagamento por parte dos segurados (Sachsleistungsprinzip), são expressōes do princípio de 'solidariedade'. A pluralidade de Caixas organizadas por profissão, ramo de produção, região ou empresa e a definiçāo do valor monetário do auxílio-doença correspondente ao salário de contribuiçāo exprimem o princípio de 'equivalência'. O apelo à responsabilidade dos indivíduos no que se refere à própria saúde apóia-se no princípio de 'subsidiariedade'.

Os diversos ramos do seguro social conformam um sistema robusto e abrangente de proteção centrado no trabalho assalariado, que tem por base principal de financiamento a renda deste mesmo trabalho assalariado, da qual são subtraídas as contribuições.

As contribuições sociais obrigatórias na Alemanha correspondem, em seu conjunto, a cerca de $42 \%$ dos salários ou mais, uma vez que são pagos de forma paritária por empregados e empregadores até o limite dos salários legalmente definido para contribuições. ${ }^{30}$

O seguro social, que é financiado por meio destas contribuiçōes, é responsável pela maior parte da proteção social garantida na Alemanha, mas esta é mais ampla e complementada por outros programas e açōes. Entre estes, a assistência social, que garante um mínimo vital e a proteção à família e à maternidade. ${ }^{31}$

30 Em 1997, as taxas de contribuição para o seguno-aposentadoria era de 20,3\%; para o segurodoença, de $3,4 \%$; para desemprego, $6,5 \%$; para cuidados de longa duração, $1,7 \%$. O seguroacidente não está incluído no cálculo, pois é diferenciado por empresá.

31 A proteção à lamília é financiada pela União. Todas as crianças recebem cerca de 200 marcos por mês (115-120 dólares) (Kindergeld) até completarem 16 anos ou conclúrem a formaçāo universitária As mães rccebem auxilio educação (Erzielhungsge/d) de 600 marcos por até 24 meses após o nascimento, dependendo da renda. 
A assistência social, outro setor importante da proteção social alemã, financiada por estados (25\%) e municípios (75\%), transfere aos habitantes uma renda mínima que garante a cobertura das necessidades básicas (BMAS, 1996b). Como já foi observado, a assistência social funda-se no princípio da subsidiariedade. Apenas quando o indivíduo e sua família estāo impossibilitados por meios próprios é que o Estado pode e deve intervir. A renda mínima é dependente da comprovação de carência, através de 'testes de meios'. Atualmente, cerca de $6 \%$ da populaçāo é beneficiária da assistência social, sendo a maioria composta por estrangeiros. Os benefícios que compõem a renda mínima correspondem a um valor entre 625 a 1.850 dólares mensais, segundo o número de dependentes e necessidades comprovadas - aquecimento, aluguel, agasalhos, atençāo à saúde. ${ }^{32}$ A renda garantida pela assistência social corresponde a cerca de $50 \%$ da renda média familiar dos operários (Schäffer, 1996a). ${ }^{33}$

\section{Seguro de acidentes de trabalho}

Tendo em mente um sistema unificado e centralizado de seguros para proteção aos grandes riscos dos grupos economicamente mais pobres, Bismark propôs ao parlamento cada um dos ramos de seguro separadamente. A primeira proposta de legislação referente à criação dos seguros sociais foi enviada por Bismark ao Conselho dos Estados (Bundesrat) $\mathrm{cm}$ janeiro de $1881 \mathrm{e}$ tinha como objetivo garantir alguma proteção contra o risco de acidentes industriais; dada a precariedade das condições de trabalho, não foi o primeiro ramo a ser criado. Como a lei referente ao seguro-doença era menos controversa, foi aprovada separadamente $\mathrm{e}$ antes do seguro de acidentes de trabalho, criado $\mathrm{cm}$ 1884. A discussão do seguro de acidentes industriais era mais difícil, pois implicava em ruptura mais radical com a forma tradicional de responsabilidade dos empregadores (Siegerist, 1943).

O objetivo desse seguro é prevenir acidentes de trabalho c docnças profissionais e, no caso em que estes ocorrem, garantir tratamento e reabilitação adequados, além de indenizações compatíveis, mediante pensões, por motivo de seqüelas ou morte.

Os provedores de seguro sāo corporaçōes de ofício, de agricultores e de marítimos, associações comunais de seguro-acidentes c os diversos níveis governamentais para seus empregados. As instituições responsáveis pelos

32 Como muitas das despesas são pagas diretamente, o beneliciário recebe valor bem menor em dinheiro.

33 À proteção social poder-se-ia somar ainda o sistema educacional, que é público e gratuito em todos os níveis, a lcgislação trabalhista e de regulação do mercado de trabalho, medidas para promoção do trabalho e incentivos ao aprendizado de outras prolissōes, legislação especial para proteção e garantia de trabalho para deficientes $\mathbf{c}$ instituições especiais para trabalho de deficientes. 
seguros de acidentes de trabalho (Berufsgenossenchaften), assim como na maioria dos outros ramos, são órgãos de administração autônoma, cuja direção é constituída por representações de empregadores e empregados, em geral, de forma paritária.

São segurados obrigatórios todas as pessoas que se encontram em alguma relação de trabalho, inclusive aprendizes e trabalhadores rurais, e, em casos especiais, trabalhadores voluntários. De igual modo, são seguradas todas as crianças que freqüentam jardins de infância, escolares e estudantes universitários. Autônomos e profissionais de saúde, tais como os funcionários públicos (Beamten), estão desobrigados de asseguramento.

O seguro social de acidentes também é financiado por contribuições. A peculiaridade deste ramo do seguro social é que apenas os empregadores contribuem para o seguro de acidentes de trabalho. As contribuiçōes consistem em uma proporção dos salários, porém, são diferenciadas conforme o grau de risco de acidentes do ramo de produçāo ao qual a empresa pertence. No caso dos provedores governamentais e das associaçōes comunais de seguro de acidentes, os benefícios são financiados com recursos fiscais (Beske; Brecht \& Reinkeimer, 1993).

\section{Seguro velhice, invalidez e mopte}

A previdência social, tal como os outros ramos do seguro, é de afiliação compulsória e financiada por meio de contribuições sociais sobre os salários, as quais sāo pagas de forma paritária por empregadores e trabalhadores e, parcialmente, por transferências da União, que correspondem a cerca de $20 \%$ das aposentadorias pagas. A taxa de contribuição para a previdência social em 1997 era de $20,3 \%$, metade paga pelo empregador c metade pelo trabalhador, descontada do salário até o limite máximo de contribuição de cerca de US\$5.000 (8.200 mar$\cos ) .^{34} \mathrm{O}$ direito à aposentadoria é definido pela idade, aos 65 anos para homens e 60 anos para as mulheres. Aposentadorias em idade inferior dependem de uma série de condiçōes e são facilitadas no caso de desemprego. O valor da aposentadoria depende do tempo e valor das contribuiçōes, correspondendo ao máximo de $70 \%$ dos salários de contribuição. ${ }^{35}$ Em outras palavras, com 45 anos de asseguramento e 65 anos de idade, o indivíduo recebe de aposentadoria cerca de $70 \%$ da sua renda de contribuição. $\mathrm{O}$ cálculo do benefício tem por base as contribuições de toda a

34 Este mesmo limite define a não obrigatoriedade de asseguramento.

3.5 Há também pensōes complementares no âmbito das empresas que ampliam esta cobertura. 
vida ativa de cada trabalhador, incluindo período de formação e licenças para educação infantil. ${ }^{36}$ A acumulaçăo da aposentadoria com salários só é permitida para maiores de 65 anos (VDR, 1997).

$\mathrm{Na}$ última reforma da previdência, em 1992, foram realizados cortes e ajustes que deveriam entrar em vigor a partir de 1997. A principal mudança foi o aumento da idade de aposentadoria das mulheres para 65 anos, igualando-a à dos homens, segundo regras de transição. Estas regras, porém, ainda não foram implementadas, tendo sido novamente postergadas.

Em 1997, o governo conservador apresentou mais uma proposta de ajuste da previdência, que consistia na introdução de um fator demográfico capaz de corrigir os reajustes das aposentadorias conforme a evolução da expectativa de vida aos 65 anos. Diminuir-se-iam os reajustes até o valor da aposentadoria atingir o patamar de $64 \%$ dos rendimentos do trabalho antcrior à aposentadoria, isto para aposentadorias com 45 anos de contribuição e aos 65 anos de idade, ou seja, propôs-se a redução do valor das aposentadorias até 2030 .

A partir de 1998, com a vitória da social-democracia e a constituiçāo de uma coalizão social-democrata/verde, os termos do debate relativo à necessidade de se estabilizar as taxas de contribuição da previdência social foram modificados, buscando-se a cobertura de prováveis déficits por meio do maior aporte de recursos fiscais. Estes recursos adicionais deveriam cobrir defasagens de contribuições referentes aos períodos de formação e licenças para educação dos filhos, por exemplo.

No debatc atual relativo a políticas sociais, surgem propostas no sentido da substituição de diferentes ramos do seguro social por um salário-cidadania. Alguns autores argumentam que sistemas centrados em contribuições vinculadas ao trabalho deveriam ser substituídos por outros, financiados por meio de recursos fiscais, dado o problema estrutural do desemprego e as mudanças no mercado de trabalho. No caso da Alcmanha, a esquerda critica esse tipo de proposição, pois seria a derrocada do atual sistema de alto nível, que poderia vir a ser substituído por protcção universal mínima.

\section{Seguro-desemprego}

Assim como os outros ramos, o seguro-desemprego é financiado por empregadores e empregados de modo paritário. A afiliação é compulsória e o salário-limite de contribuição é o mesmo que para a previdência social. A

36 Para o cálculo do valor da aposentadoria são estimados todos os anos de asseguramento. $\mathrm{O}$ salário individual é comparado com os rendimentos médios do trabalho no ano de referência. Se o indivíduo tiver contribuído na média, recebe um ponto por ano. Seu número total de pontos é multiplicado por um valor básico de aposentadoria. 
duração do seguro-desemprego depende do tempo de trabalho anterior e da idade do contribuinte. ${ }^{37}$

O nível do benefício é de cerca de $60 \%$ do salário líquido médio anterior e de $67 \%$ para trabalhadores com filhos. Após o término da vigência do seguro-desemprego, o desempregado tem direito à 'ajuda-desemprego' pelo período de um ano. A 'ajuda-desemprego' é mais baixa e corresponde a cerca de $53 \%$ do salário médio da categoria, sendo financiada por meio de impostos gerais. Após este período, caso o trabalhador continue desempregado, poderá recorrer à assistência social.

O seguro-desemprego é o ramo do seguro social que tem apresentado maior expansão de gastos. Sua taxa de contribuição elevou-se muito nas últimas décadas em decorrência do crescente desemprego. Entre 1982 e 1997, a taxa de contribuição duplicou e passou a ser de $6,5 \%$. Nos últimos anos, fez-se uma série de cortes no seguro-desemprego, diminuindo prazos e nível dos benefícios.

Em 1981, o valor do seguro-desemprego para solteiros era de $68 \%$ do salário médio e passou a ser um pouco menor do que $60 \%$. Mesmo assim, os gastos com seguro-desemprego aumentaram nos últimos anos. As despesas do Departamento do Trabalho, um dos setores do Ministério do Trabalho e da Ordem Social ao qual está vinculado o seguro-desemprego, incluídos os gastos com outras medidas de promoção e geraçāo de empregos, de aperfeiçoamento e reciclagem profissional, correspondiam, em 1995, a 2,8\% do PIB (BMAS, 1996a).

\section{Seguro social para cuidados de longa duração}

O quinto e mais recente ramo do seguro social, o seguro para cuidados de longa duração (Pflegeversicherung) foi instituído em 1994 (lei de 28.05.94) e visa a garantir proteção nas situações de perda da autonomia por velhice ou doença crônica.

Este ramo assegura o pagamento de cuidados para pessoas que estão incapacitadas de realizar suas necessidades funcionais por idade ou deficiência. $\mathrm{O}$ valor dos benefícios é definido a partir do estágio de impossibilidade, isto é, do grau de dependência de cuidados de enfermagem de cada um.

O seguro garante cuidados domiciliares, na forma de repasses financeiros ao paciente ou na forma de prestação por serviços credenciados e cuidados em regime de internação em instituições específicas. O pagamento pode ser feito ao próprio segurado, para que este remunere uma pessoa, ou o próprio escolhe um serviço credenciado. A contribuição é de $1,7 \%$ dos salários até o limite máximo do

37 A duração do benefício aumenta, de modo gradual, a partir dos 42 anos de idade. Quem trabalha, por exemplo, durante dois anos antes de ficar desempregado, recebe seguro-desemprego por un ano. 
salário de contribuição idêntico ao do seguro-saúde. Embora a taxa seja repartida meio a meio entre empregadores e empregados, considera-se que o seguro não é financiado paritariamente. ${ }^{38}$

As regras de afiliação e de organização deste seguro social săo as mesmas do Seguro Social de Doença (GKV). Ainda que seja um ramo independente do seguro social que conta com contribuiçōes próprias, o asseguramento para cuidados de longa duração utiliza a estrutura do Seguro Social de Doença. A afiliação ao seguro é feita junto às instituiçōes de provisão do seguro social de doença. O financiamento e a contabilização de gastos dos dois ramos, porém, são independentes.

À diferença do Seguro Social de Doença, que tem suas contribuições definidas pelos órgãos da administração autônoma, as contribuiçōes do seguro social para cuidados de longa duração são fixadas por legislaçāo, o que permite intervençāo direta do legislador.

Além de resolver um problema de necessidades básicas/vitais, a criaçāo do seguro de cuidados de longa duração aliviou o Seguro Social de Doença e a assistência social desse tipo de gastos. Desse modo, para alguns autores, a criaçāo desse ramo do seguro social estaria de acordo com o objetivo de estabilização das taxas de contribuição do GKV (Döhler, 1994). ${ }^{39}$

Este mais recente ramo do seguro social encontra-se ainda em fase de implementação. Entrou em vigor em 1995 para a atençāo ambulatorial e, em 1997, passaram a ser cobertos cuidados de longa duração em regime de internação. A cobertura de mais uma necessidade vital por meio da criação deste ramo de seguro social é indicativa da permanente preocupação com a proteção social e da solidez do sistema de welfare na Alemanha.

38 Os empregadores obtiveram como compensação às suas contribuiçōes a renúncia por parte dos trabalhadores a um feriado, ou seja, trabalham um dia a mais por ano.

39 Anteriomente, em muitos casos, aposentadorias insulicientes para pagar asilo ou cuidados de enfermagem para velhos lizeram com que a assistência social dos municípios licasse com este encargo. Em 1989, os cuidados, no caso de dependência severa, foram incluídos no catálogo de ações garantidas pelo Seguro Social de Docnça (GKV). 